\title{
PENGGUNAAN KUNINGAN SEBAGAI BAHAN CATALYTIC CONVERTER TERHADAP EMISI GAS BUANG dan PERFORMA MESIN SUZUKI SHOGUN AXELO 125
}

\author{
Syahruji ${ }^{1)}$, Abdul Ghofur ${ }^{2}$ \\ ${ }^{1,2}$ Program Studi Teknik Mesin \\ Fakultas Teknik Universitas Lambung Mangkurat \\ Jl. Akhmad Yani Km. 36 Banjarbaru, Kalimantan Selatan, 70714 \\ e-mail: psyahruji@gmail.com
}

\begin{abstract}
The purpose of this study was to determine the use of brass plate catalysts in the exhaust channel of Suzuki Shogun Axelo 125 in 2010. This study used an experimental method. The population in this study was a Suzuki Shogun Axelo 125 motorbike in 2010, the research data was a number showing gas content remove $\mathrm{CO}_{2}, \mathrm{CO}, \mathrm{HC}$. This research was carried out in the banjarmasin environment office using a gas analyzer and was also conducted at the Banjarmasin plug and play workshop by using a dynamometer. The technique used in data collection was the variation in rpm and number of plates. (1) The results of this study are: Forming a catalytic converter with plate variation 8 (eight) so that the level of CO2 emission reduction is maximum of $52,7 \%$, the level of $\mathrm{CO}$ emission reduction is $82.23 \%$, and the level of $\mathrm{HC}$ emission reduction is $74,08 \%$. The form of catalytic converter with plate variation 6 (six), the maximum $\mathrm{CO}_{2}$ emission reduction level is $29,56 \%$, the level of $\mathrm{CO}$ emission reduction is $49.32 \%$, and the level of $\mathrm{HC}$ emission reduction is $82,92 \%$. (2) By using catalytic converters with plate variation 8 (eight) to produce power of 8.045 $h p$ and torque of 8,833 $n / m$ and for catalytic converters with plate variation 6 (six) producing power of $7.661 \mathrm{hp}$ and torque of $8.493 \mathrm{n} / \mathrm{m}$.
\end{abstract}

Keywords: Catalytic Converter, Emission, Exhaust, $\mathrm{CO}_{2} \mathrm{CO} \mathrm{HC}$

\section{PENDAHULUAN}

Pertumbuhan kendaraan bermotor di Indonesia yang terus meningkat telah menyebabkan persoalan serius dalam hal peningkatan pencemaran udara. Hal ini disebabkan karena tidak sebandingnya angka pertumbuhan jalan yang hanya 2 per tahun jauh sekali dengan angka pertumbuhan kendaraan bermotor yang telah mencapai 20 per tahun. Pertumbuhan tersebut jelas akan membawa pengaruh meningkatnya pemakaian Bahan Bakar Minyak dan dengan sendirinya polusi udara akibat dari emisi gas buang kendaraan bermotor menjadi tidak dapat terelakkan lagi.

Meningkatnya jumlah kendaraan bermotor setiap tahun berdampak terhadap peningkatan gas buang, sehingga menghasilkan banyak polusi udara. Gas buang yang dihasilkan dari jutaan knalpot akan mengakibatkan berkurangnya kualitas udara dan dapat mencemari lingkungan. Oleh sebab itu, diperlukan kendaraan yang ramah lingkungan dengan cara meminimalkan kandungan $\mathrm{CO}$ dan $\mathrm{HC}$ pada emisi gas buang kendaraan salah satu teknologi yang dapat digunakan untuk mereduksi emisi gas buang kendaraan bermotor yaitu dengan penambahan catalytic converter pada saluran buang kendaraan.

Dari data badan pusat statistik perkembangan jumlah kendaraan selalu menigkat setiap tahunnya, pada tahun 2013 jumlah kendaraan di indonesia sebanyak 104.118.969 unit dan jenis kendaraan yang paling banyak yaitu sepeda motor dengan 84.732 .652 unit. Dari data tersebut maka potensi yang 
paling besar dalam mengurangi jumlah polusi udara di indonesia salah satunya dengan memodifikasi saluran gas buang sepeda motor menggunakan catalytic converter.

Berdasarkan cara pemikiran dan penelitian sebelumnya,salah satu teknologi yang dapat digunakan untuk mereduksi emisi gas $\mathrm{CO}$ dan $\mathrm{HC}$ adalah dengan pemasangan catalytic converter yang dipasang pada sistem saluran pembuangan emisi gas atau knalpot. Oleh sebab itu pada penelitian ini bertujuan untuk menguji katalis kuningan dengan variasi bentuk catalytic converter ( Bosch, 1998 ).

\section{Emisi Gas Buang Kendaraan}

Emisi gas buang kendaraan adalah sisa hasil pembakaran yang dihasilkan oleh pembakaran di dalam mesin kendaraan bermotor. Gas sisa pembakaran mesin bersifat racun dan akan merusak lapisan ozon serta menjadi penyebab utama adanya pemanasan global (global warming). Beberapa gas yang ditimbulkan oleh sisa pembakaran mesin adalah :
1. Karbon monoksida (CO)
2. Karbon dioksida (CO2)
3. Air $(\mathrm{H} 2 \mathrm{O})$
4. Timbal $(\mathrm{Pb})$
5. Nitrogen Oksida (NOx)
6. Hidrokarbon $(\mathrm{HC})$

Emisi gas buang yang sangat dominan dihasilkan oleh kendaraan bermotor salah satunya adalah gas karbon monoksida $(\mathrm{CO})$ dan gas lainnya seperti yang terlihat dalam Tabel 1.

Tabel 1. Emisi gas buang kendaraan

\begin{tabular}{|l|c|c|c|c|c|c|}
\hline \multirow{2}{*}{ Sumber } & \multicolumn{6}{|c|}{ Polusi (dalam juta ton/tahun) } \\
\cline { 2 - 8 } & $\mathrm{CO}$ & Part & $\mathrm{SO} \times$ & $\mathrm{HC}$ & $\mathrm{NO}_{\mathrm{x}}$ & Total \\
\hline Transportasi & 69,1 & 1,4 & 0,9 & 7,8 & 9,1 & 88,3 \\
\hline Pembakaran bahan bakar & 2,1 & 1,4 & 19,0 & 0,2 & 10,6 & 33,3 \\
\hline Proses industri & 5,8 & 3,7 & 3,8 & 10,8 & 0,7 & 24,8 \\
\hline Pembuangan limbah padat & 2,2 & 0,4 & 0,0 & 0,6 & 0,1 & 3,3 \\
\hline $\begin{array}{l}\text { Lain-lain (kebakaran hutan, } \\
\text { pertanian) }\end{array}$ & 6,2 & 0,9 & 0,0 & 2,4 & 0,2 & 9,7 \\
\hline Total & 85,4 & 7,8 & 23,7 & 21,8 & 20,7 & 159,4 \\
\hline
\end{tabular}

Pengujian untuk menghitung jumlah emisi gas buang yang terabsorbsi dapat menggunakan alat gas analizer. Alat gas analizer dapat menunjukkan kadar zat-zat polutan yaitu $\mathrm{CO}, \mathrm{CO} 2$, NOX, O2, dan $\mathrm{HC}$ yang keluar dari system pembuangan (exhaust system) kendaraan bermotor. Hasil pengukuran alat gas analizer dapat langsung diketahui melalui print out yang langsung keluar dari alat gas analizer. Hasil pengukuran meliputi kadar CO (\%volume), HC (ppm volume), CO2 (\%volume), dan O2 (\%volume). Gas analyzer dihubungkan dengan motor melalui pipa listrik yang dihubungkan ke baterai dan mesin motor, kemudian motor dihidupkan sementara gas analizer di set ke posisi nol. Sensor dimasukkan ke dalam knalpot kendaraan dan secara otomatis alat bekerja serta hasil langsung tertera pada monitor alat yang digunakan.

\section{Gas Karbon Monoksida (CO)}

Karbon monoksida (CO) merupakan polutan yang tidak berwarna dan tidak berbau. Karbon monoksida merupakan racun. Apabila CO bercampur dengan oksigen dan terhirup oleh manusia, maka $\mathrm{CO}$ akan bereaksi dengan hemoglobin 
$(\mathrm{Hb})$ yang menyebabkan kemampuan darah untuk mentransfer oksigen menjadi berkurang (Swisscontact, 2000).

Gas Karbon monoksida (CO) dihasilkan dari pembakaran yang tidak sempurna akibat campuran bahan bakar dan udara yang terlalu kaya (Swisscontact, 2000). Untuk mengurangi CO, perbandingan campuran harus dikurangi atau dibuat miskin (excess air). Namun akibatnya gas hidrokarbon $(\mathrm{HC})$ lebih mudah timbul serta output mesin menjadi berkurang (Swisscontact, 2000). Bila karbon di dalam bahan bakar terbakar dengan sempurna, akan terjadi reaksi yang menghasilkan $\mathrm{CO}_{2}$ sebagai berikut:

$\mathrm{C}+\mathrm{O}_{2} \rightarrow \mathrm{CO}_{2}$

Apabila unsur oksigen udara tidak cukup terjadi pembakaran tidak sempurna sehingga karbon di dalam bahan bakar terbakar dengan proses sebagai berikut:

$\mathrm{C}+1 / 2 \mathrm{O}_{2} \rightarrow \mathrm{CO}$

\section{Gas Hidrokarbon (HC)}

Bensin yang digunakan sebagai bahan bakar untuk proses oksidasi $\mathrm{CO}$ dan $\mathrm{HC}$ dimodelkan hanya mengandung iso-oktana. Iso-oktana dipilih sebagai komponen model dengan karena banyak digunakan sebagai komponen model dalam kajian yang melibatkan motor bakar (internal combustion engines) (Marin, 2009). Reaksi oksidasi untuk HC jenis iso-oktana dinyatakan dalam Persamaan sebagai berikut:

$\mathrm{C}_{8} \mathrm{H}_{18}+12,5 \mathrm{O}_{2} \rightarrow 8 \mathrm{CO}_{2}+9 \mathrm{H}_{2} \mathrm{O}$ berikut:

Sumber emisi hidrokarbon $(\mathrm{HC})$ dapat dibagi menjadi dua bagian, sebagai

1. Bahan bakar yang tidak terbakar dan keluar menjadi gas mentah.

2. Bahan bakar terpecah karena reaksi panas berubah menjadi gugusan hidrokabron $(\mathrm{HC})$ lain yang keluar bersama gas buang.

Sebab utama timbulnya hidrokarbon $(\mathrm{HC})$ adalah:

1. Sekitar dinding-dinding ruang bakar bersuhu rendah, dimana suhu itu tidak mampu melakukan pembakaran.

2. Missing (missfire)

3. Adanya overlaping katup (kedua katup bersama-sama terbuka) sehingga merupakan gas pembilas atau pembersih.

Hidrokarbon memiliki karakteristik yaitu sebagai berikut:

1. Hidrokarbon jenuh (parafin). Hidrokarbon jenuh umumnya tidak berbau, mengandung efek narkotik dan menyebabkan iritasi ringan selaput lender.

2. Hidrokarbon tak jenuh (olefin, asetilen). Hidrokarbon tak jenuh umumnya agak berbau dan terkadang menyebabkan iritasi ringan pada selaput lender.

3. Hidrokarbon beraroma. Hidroakrbon jenis ini berbau, dapat meracuni urat saraf, pada konsumsi rendah menyebabkan iritasi pada mata dan hidung.

\section{Catalytic Converter}

Catalytic converter merupakan salah satu alternatif teknologi yang dapat digunakan untuk menurunkan polutan dari emisi kendaraan bermotor, khususnya motor berbahan bakar bensin (Heisler, 1995 dan Husselbee, 1985). Catalytic converter berfungsi untuk mempercepat oksidasi emisi hidrokarbon $(\mathrm{HC})$ dan karbon monoksida (CO). Tujuan pemasangan catalytic converter adalah merubah polutan-polutan yang berbahaya seperti $\mathrm{CO}$, dan $\mathrm{HC}$ menjadi gas yang 
tidak berbahaya seperti karbon dioksida (CO2), dan uap air $(\mathrm{H} 2 \mathrm{O})$ melalui reaksi kimia. Pengkonversian polutan-polutan berbahaya tersebut tergambar pada reaksi sebagai berikut:

1. $\mathrm{CO}+1 / 2 \mathrm{O}_{2} \rightarrow \mathrm{CO}_{2}$

2. $\mathrm{HC}+\mathrm{O}_{2} \rightarrow \mathrm{CO}_{2}+\mathrm{H}_{2} \mathrm{O}$

Catalytic converter terdiri atas bahan-bahan yang bersifat katalis yaitu bahan yang bisa mempercepat terjadinya reaksi kimia yang tidak mempengaruhi keadaan akhir kesetimbangan reaksi dan komposisi kimia katalis. Katalis dapat berfungsi sebagai zat pengikat. Contoh katalis yang berfungsi sebagai zat pengikat yaitu logam-logam seperti platinum (Pt), kromium $(\mathrm{Cr})$, kuningan (CuZn), dan nikel (Ni). Permukaan logam-logam ini memiliki kemampuan mengikat zat yang akan bereaksi sehingga terbentuk spesi yang reaktif. Katalis logam paduan CuZn mempercepat reaksi-reaksi gas dengan cara membentuk ikatan lemah antara gas dan atom-atom logam pada permukaan (Amin, 2010). Proses ini disebut adsorpsi. Gas-gas yang terikat pada permukaan logam paduan CuZn lebih mudah bereaksi dibandingkan jika gas-gas tersebut berada di udara. Setelah terjadi reaksi, produk hasil reaksi melepas ikatannya dengan permukaan logam paduan CuZn. Proses ini disebut desorpsi. Jumlah katalis setelah reaksi berlangsung akan sama dengan jumlah katalis sebelum terjadinya reaksi.

\section{Cara kerja catalytic converter}

Seiring dengan berlakunya standar emisi gas buang untuk produk mobil dan sepeda motor di Indonesia mulai 2007, catalytic converter menjadi peranti yang wajib dipasang pada kendaraan produksi terbaru. Alat ini dirancang untuk mengurangi gas polutan sisa pembakaran mesin kendaraaan bermotor. Catalytic converter merupakan salah satu inovasi terbesar di industri otomotif. Pasalnya, peranti ini mampu mengubah zat-zat hasil pembakaran seperti, hidrokarbon $(\mathrm{HC})$, karbon oksida $(\mathrm{CO})$, dan NOx, menjadi zat yang lebih ramah lingkungan. Berdasarkan data Manufactures of Emission Controls Association (MECA) AS sejak tahun 1970-an hingga saat ini, catalytic converters telah membantu mengurangi bahan polutan sebanyak 1,5 miliar ton di AS dan tiga miliar ton di seluruh dunia.

Bentuk catalytic converter seperti tabung bentuknya mirip sarang tawon. Bahannya terbuat dari keramik dengan ukuran lubang penyaring antara satu hingga dua $\mathrm{mm}$. Secara umum ada dua tipe catalytic converter yang dipakai, yaitu jenis pellet dan monolithic. Jenis monolithic merupakan catalytic converter yang banyak dipakai saat ini. Alasannya, jenis tersebut memiliki tahanan gas buang yang kecil, lebih ringan, dan cepat panas dibandingkan jenis pellet.

Untuk mengurangi gas polutan, catalytic converter menggunakan beberapa bahan baku. Berdasarkan bahan baku yang dipakai, catalytic converter bisa dibagi menjadi dua model, yaitu oxidation catalyst (OC) dan three way catalyst (TWC). Jenis OC menggunakan material platinum dan paladium, yang dapat mengurangi $\mathrm{CO}$ dan $\mathrm{HC}$. Sedangkan TWC mengandung platinum dan rhodium yang mampu mengurangi $\mathrm{CO}, \mathrm{HC}$.

Catalytic converter ditempatkan di belakang exhaust manifold atau diantara muffler dengan header. Alasannya, catalytic converter cepat panas ketika mesin dinyalakan. Selain itu, sensor bisa segera bekerja untuk menginformasikan kebutuhan campuran bahan bakar udara yang tepat ke Engine Control Machine (ECM). Peranti catalytic converter baru bekerja efektif ketika kondisinya panas.

Pipa buang adalah pipa baja yang mengalirkan gas sisa pembakaran dari exhaust manifold ke udara bebas. Konstruksinya dibagi menjadi beberapa bagian, yaitu pipa bagian depan, tengah, dan belakang. Susunannya sengaja 
dibuat demikian untuk mempermudah saat penggantian catalytic converter atau muffler, tanpa perlu melepas keseluruhan konstruksi sistem pembuangan.

Muffler berfungsi untuk mengurangi tekanan dan mendinginkan gas sisa pembakaran. Ini karena gas sisa pembakaran yang dikeluarkan dari mesin memiliki tekanan cukup tinggi, sekira 3 hingga $5 \mathrm{~kg} / \mathrm{cm} 2$ Sedangkan suhunya bisa mencapai 600 hingga 800 Besaran panas ini kira-kira 34\% dari energi panas yang dihasilkan mesin. Kalau gas ini langsung disalurkan ke udara luar tanpa muffler, gas akan mengembang dengan cepat diiringi dengan suara ledakan yang cukup keras (Geomorphosis, 2011).

\section{Mekanisme reaksi catalytic converter}

Reaksi katalis berlangsung dengan menggunakan oksigen sebagai oksidanya. Reaksi tersebut berlangsung pada permukaan katalis oksida logam tersebut. Reaksi pada permukaan tersebut dapat dijelaskan menurut (Razif, M., J. Nugroho, et al, 2005).

a. Mekanisme Mars-Van Krevelen Oksidasi CO berlangsung melalui adsorpsi $\mathrm{CO}$ pada katalis diikuti terjadinya reaksi $\mathrm{CO}$ dengan atom $\mathrm{O}$ dari katalis kemudian melepas $\mathrm{CO} 2$ sebagai hasil reaksi. (Razif, M., J. Nugroho, et al, 2005).

b. Mekanisme Langmuir-Hinshelwood Molekul CO dapat mengalami kondensasi di atas permukaan katalis dan atom oksigen berada disampingnya, selanjutnya keduanya berinteraksi di permukaan katalis dan terbentuk ikatan baru (Razif, M. J. Nugroho, et al, 2005).

c. Mekanisme Eley-Rideal Hanya oksigen teradopsi pada permukaan katalis, sedangkan carbon monoksida dapat mengalami ikatan dengan oksigen selama proses tumbukan (Razif, M. J. Nugroho, et al, 2005).

\section{Kuningan (CuZn)}

Kuningan adalah logam yang merupakan campuran dari tembaga dan seng. Tembaga merupakan komponen utama dari kuningan, dan kuningan biasanya diklasifikasikan sebagai paduan tembaga. Warna kuningan bervariasi dari coklat kemerahan gelap hingga ke cahaya kuning keperakan tergantung pada jumlah kadar seng. Seng lebih banyak mempengaruhi warna kuningan tersebut.

Komponen utama kuningan adalah tembaga. Jumlah kandungan tembaga bervariasi antara 55\% sampai dengan 95\% menurut beratnya tergantung pada jenis kuningan dan tujuan penggunaan kuningan. Kuningan yang mengandung persentase tinggi tembaga terbuat dari tembaga yang dimurnikan dengan cara elektrik, yang setidaknya menghasilkan kuningan murni 99,3\% agar jumlah bahan lainnya bisa di minimalkan. Kuningan yang mengandung persentase rendah tembaga juga dapat dibuat dari tembaga yang dimurnikan dengan elektrik, namun lebih sering dibuat dari scrap tembaga. Ketika proses daur ulang terjadi persentase tembaga dan bahan lainnya harus diketahui sehingga produsen dapat menyesuaikan jumlah bahan yang akan ditambahkan untuk mencapai komposisi kuningan yang diinginkan.

Komponen kedua dari kuningan adalah seng (Zn). Jumlah seng bervariasi antara $5 \%$ sampai dengan $40 \%$ menurut beratnya tergantung pada jenis kuningan. Kuningan dengan persentase seng yang lebih tinggi memiliki sifat lebih kuat dan lebih keras, tetapi juga lebih sulit untuk dibentuk, dan memiliki ketahanan yang kurang terhadap korosi. Seng yang digunakan untuk membuat kuningan bernilai komersial dikenal sebagai spelter. 
Suhardi (1998: 50) seng memiliki sifat sifat antara lain: berat jenisnya 6,9 7,2 titik cairnya 419 , titik didihn 420 , dan tahan udara lembab. Seng biasa dipakai untuk melapisi pelat besi agar tidak berkarat. Paduan tembaga dan seng dinamakan brass. Penambahan sedikit timah, nikel, mangan, aluminium, dan unsur-unsur lain dalam paduan tembaga seng dapat mempertinggi kekerasan dan kekuatan serta tahan korosi (special - brass).

Dengan perpaduan kedua jenis logam tersebut, maka kuningan $(70 \% \mathrm{Cu}$, $30 \% \mathrm{Zn}$ ) memungkinkan untuk digunakan sebagai katalis pada saluran buang karena mempunyai konduktivitas termal sebesar $110 \mathrm{~W} / \mathrm{m}$. oK dan melting point 915 . Semakin tinggi konduktivitas termal dan melting point, maka semakin bagus pula bahan tersebut digunakan sebagai katalis.

\section{METODE PENELITIAN}

Material substrat untuk konstruksi bagian dalam terbuat dari Logam Kuningan yang berbentuk plat berukuran $30 \times 120 \mathrm{~cm}$ dengan ketebalan 0,5 mm. Plat tersebut kemudian dipotong dan disesuaikan dengan bentuk chasingnya dan diberi lubang berdiameter $8 \mathrm{~mm}$, jarak antar lubang $4 \mathrm{~mm}$ dan jumlah plat variasi 6 dan jumlah plat variasi 8 dengan jumlah lubang 17, seperti yang terlihat dalam Gambar 1.

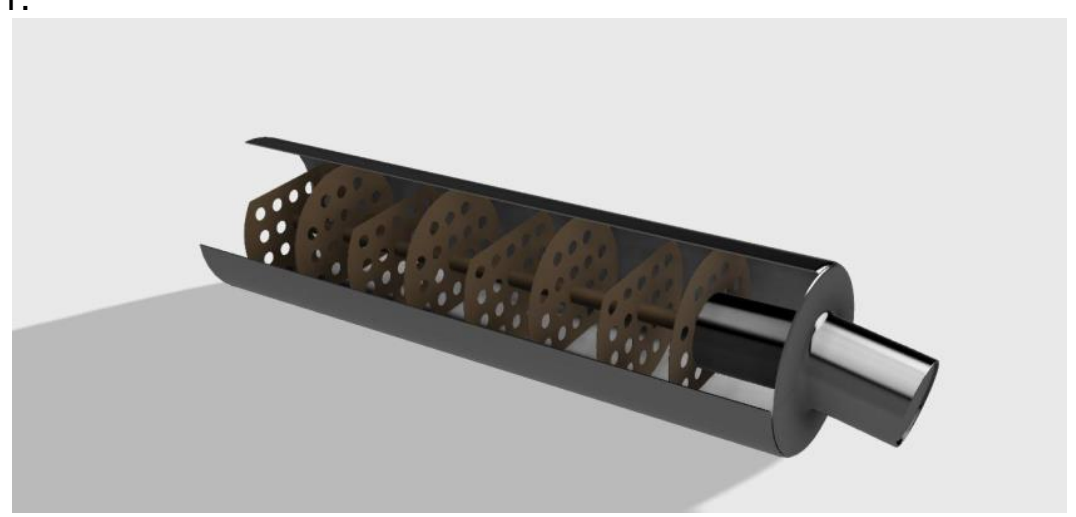

Gambar 1. Letak Pemasangan Catalytic Converter Pada Shogun Axelo 125

\section{Alat Penelitian}

Adapun alat yang akan digunakan untuk penelitian ini sebagai berikut:

1. Gas analyser

Alat untuk mengetahui kadar gas buang yang dikeluarkan motor melalui saluran buang (exhaust manifold). Misalnya gas $\mathrm{O}_{2}, \mathrm{CO}, \mathrm{CO}_{2}$, dan $\mathrm{HC}$.

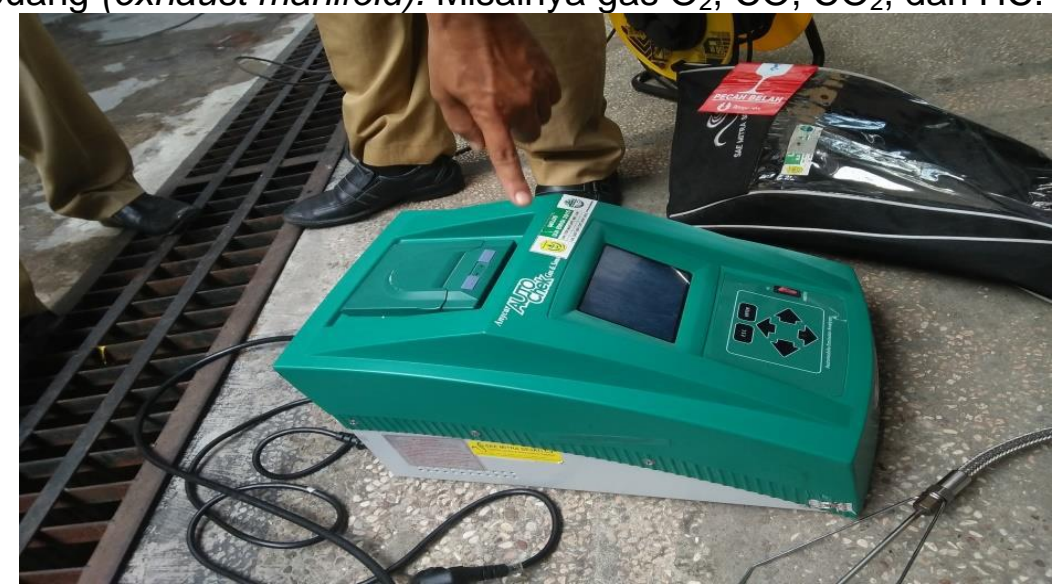

Gambar 2. Gas Analyzer 
2. Kendaraan Uji

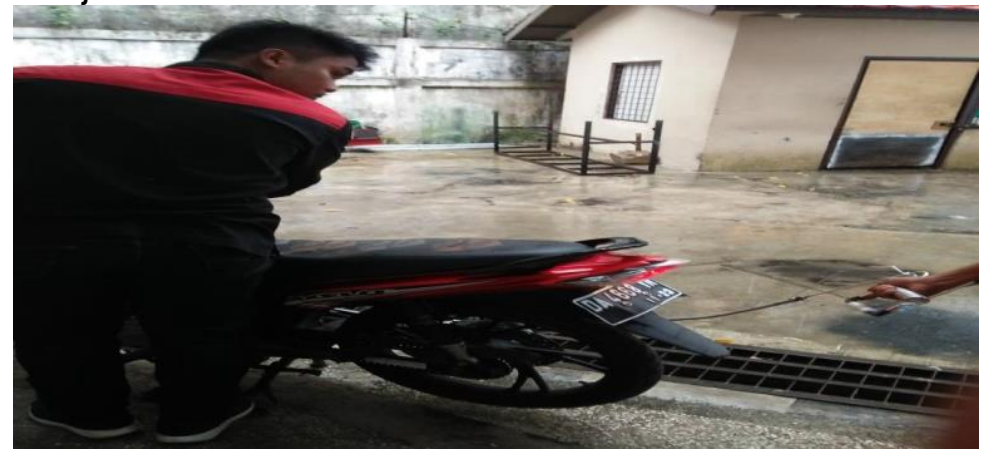

Gambar 3. Kendaraan Uj Shogun Axelo 125 Tahun 2010

\section{Tachometer}

Tachometer, yaitu alat yang berfungsi untuk mengetahui besarnya putaran mesin dalam satuan rpm (rotation per minutes).

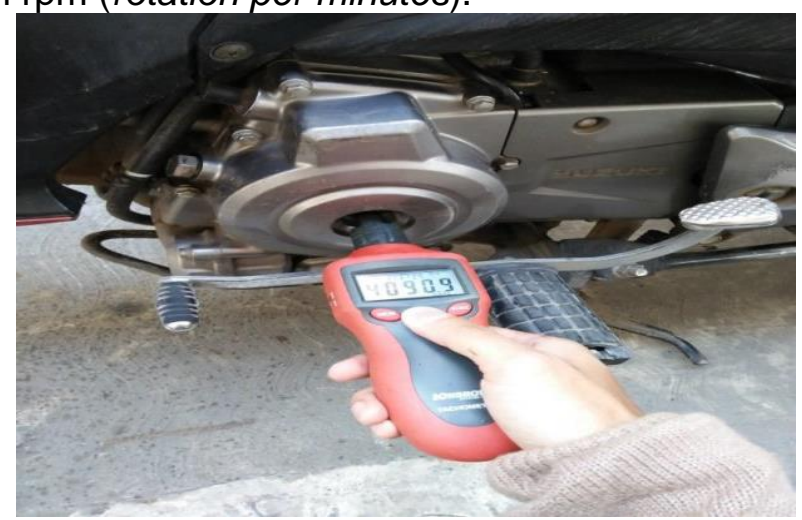

\section{Gambar 4.Tachometer}

Alat ini digunakan untuk mengetahui putaran mesin pada saat melakukan penelitian, yaitu putaran idle. Tachometer yang digunakan mempunyai spesifikasi sebagai berikut :

Tipe : KW06-303

Fitur : 5 digit dengan tampilan $L C D$, Tingkat ketelitian $0,05 \%$

Dimensi : $160 \times 72 \times 37 \mathrm{~mm}$

Berat : 225 gram

Aksesoris : Sensor pada ujung Baterai : 1.5V AA

4. Katalis kuningan yang digunakan dalam penelitian berupa plat kuningan dengan menvariasikan jumlah plat kuningan, yaitu: 6 plat,dan 8 plat.

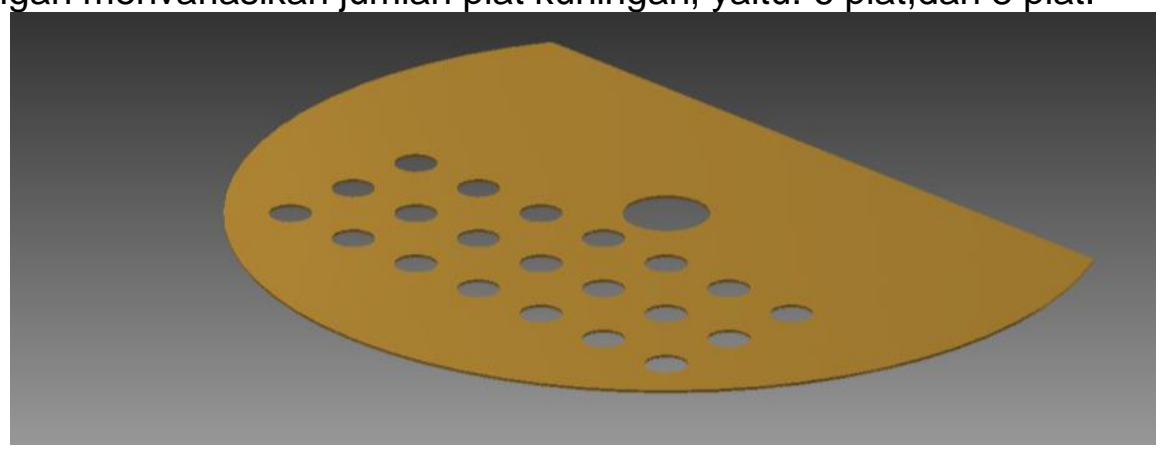

Gambar 5. Bentuk Plat Kuningan 


\section{Urutan Langkah Eksperimen}

Tahap eksperimen dalam penelitian ini dapat di lihat dalam Gambar 6, yaitu bagan aliran proses sebagai berikut:

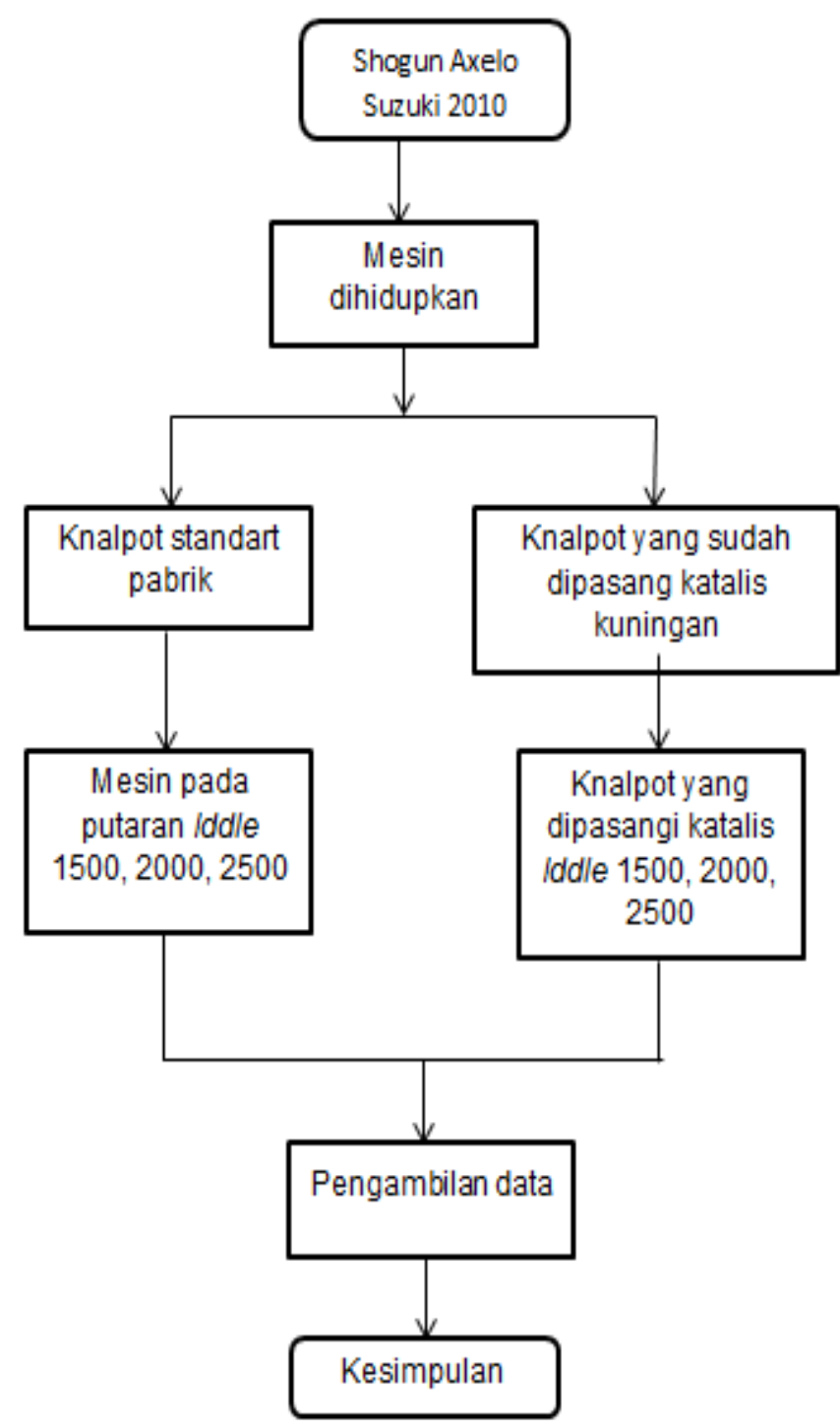

Gambar 6. Bagan aliran proses eksperimen

\section{Tahap Penelitian}

1. Persiapan kondisi mesin

a. Mengganti minyak pelumas dan pemeriksaan kebocoran.

b. Mengganti atau membersihkan saringan udara.

c. Servis karburator.

d. Mengganti busi dan pemeriksaan celah busi.

e. Stel katub.

2. Langkah pemanasan mesin

a. Menghidupkan mesin.

b. Panaskan mesin dalam kondisi idle (950-1000 rpm) sampai suhu oli mesin $700 \mathrm{C}$.

c. Memeriksa kondisi mesin uji dan memastikan semua berjalan dengan normal dan instrument berjalan dengan baik.

d. Mesin siap untuk diuji emisi gas buangnya. 
3. Kalibrasi gas analyzer
a. Alat ukur dinyalakan dengan menghunungkan kabel power ke sumber listrik dan tombol "on" ditekan.
b. Colok ukur (probe sensor) dimasukkan pada mulut knalpot.
c. Kemudian dibiarkan selama 15 menit sehingga alat ukur dapat melakukan pemanasan dalam menyerap gas buang sebagai blanko untuk melakukan pengukuran.
d. Setelah itu display alat ukur akan menunjukkan auto zero yang artinya sedang melakukan kalibrasi otomatis.
e. Setelah itu display alat ukur akan menunjukkan angka atau nilai emisi dari kendaraan yang diuji.
f. Tekan "menu" lalu enter menu "print" untuk mencetak hasil pengujian tersebut. g. Setelah itu display alat ukur akan menunjukkan autozero, artinya mesin melakukan kalibrasi otomatis dan layar akan menunjukkan angka 0 (nol).

4. Pengujian tanpa penggunaan katalis kuningan
a. Mesin dipanaskan sampai suhu oli mesin 700 .
b. Mesin dalam keadaan idle dan probe sensor dimasukkan ke mulut knalpot.
c. Setelah alat ukur menunjukkan nilai emisi gas buang, cetak hasilnya.
d. Setelah selesai, lepaskan probe sensor dari mulut knalpot. bersih, lalu lakukan lagi pengulangan pengujian sampai 5 kali dengan langkah yang sama.
e. Tunggu 20-30 menit agar gas buang sisa yang masuk pada alat ukur

5. Pengujian dengan katalis kuningan
a. Variasi jumlah plat. Ada 3 variasi jumlah catalytic converter, yaitu: knalpot standar, knalpot yang dipasangi katlis 6 plat, dan 8 plat.
b. Untuk melakukan pengujian pada mesin uji katalis, kuningan dipasang pada saluran buang kendaraan uji.
c. Pada kondisi mesin Pengujian dengan katalis kuningan yaitu dengan plat dan lubang plat kuningan dingin, lakukan pemanasan terlebih dahulu.
d. Setelah itu lakukan pengujian emisi gas buang dengan langkah yang sama dengan langkah pengujian tanpa katalis kuningan.
e. Untuk masing-masing variasi, pengujian dilakukan pengulangan sampai 3 kali.

\section{HASIL DAN PEMBAHASAN}
Hasil Pengujian Catalytic Converter Terhadap Emisi Gas Buang $\mathrm{CO}_{2}$ Dengan Variasi RPM

Pengambilan data dilakukan sebanyak tiga kali pada tiap putaran lalu dirata-rata kemudian ditabelkan dan dibuat grafik, putaran diambil antara iddle sampai 5000 rpm. Hasil emisi $\mathrm{CO}_{2}$ dapat dilihat pada Gambar 7. 


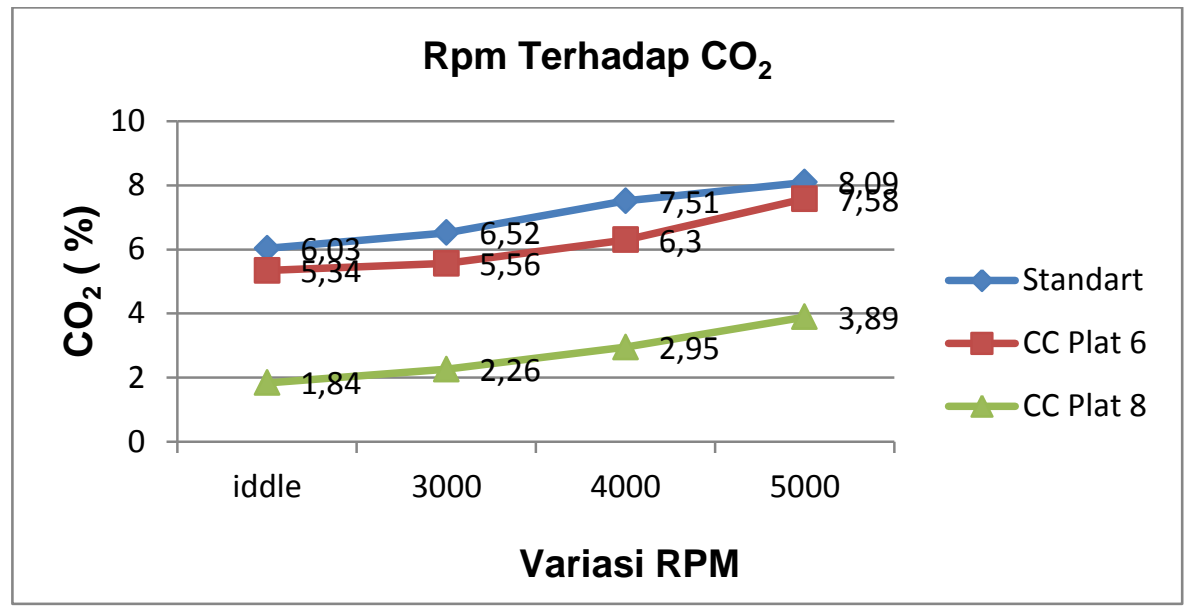

Gambar 7. Emisi Gas Buang $\mathrm{CO}_{2}$

Dari Gambar 7 dapat dilihat bahwa penggunaan Catalytic Converter dengan katalis kuningan ternyata mampu menaikkan konsentrasi emisi gas buang karbon dioksida $\left(\mathrm{CO}_{2}\right)$ secara signifikan dibandingkan dengan yang tidak menggunakan Catalytic Converter, motor yang digunakan untuk pengujian adalah shogun axelo 125 tahun 2010, Dengan penggunaan knalpot standar atau tanpa catalytic converter, dan menggunakan plat berbentuk 6 dan juga plat 8 dapat dilihat bahwa kandungan gas $\mathrm{CO}_{2}$ akan meningkat seiring dengan kenaikan RPM.

Dari Gambar 7 terlihat bahwa kadar gas $\mathrm{CO}_{2}$ bernilai rendah pada RPM rendah dan kemudian terus naik pada saat RPM semakin tinggi. Hal ini terjadi disebabkan karena pada RPM rendah atau saat awal penyalaan kandungan gas $\mathrm{CO}_{2}$ yang terbentuk dapat keluar dari saluran gas buang dengan baik serta terjadinya adsorbsi yang baik pada awal pemakaian kuningan. Tetapi seiring dengan waktu penyalaan mesin yang semakin lama konsentrasi gas $\mathrm{CO}_{2}$ akan semakin tinggi sehingga kadar $\mathrm{CO}_{2}$ akan terus meningkat pada saluran gas buang dan kuningan mulai mengalami kejenuhan. Kenaikan kadar $\mathrm{CO}_{2}$ ini juga disebabkan karena terlalu rapatnya katalis yang menyebabkan gas buang tidak dapat keluar dengan sempurna sedangkan $\mathrm{CO}_{2}$ yang keluar dari ruang bakar terus bertambah pada saluran gas buang, sehingga menyebabkan proses katalisasi tidak dapat berlangsung dengan sempurna.

\section{Hasil Pengujian Catalytic Converter Terhadap Emisi Gas Buang CO dengan} Variasi RPM

Hasil emsi gas buang CO dapat dilihat pada Gambar 8.

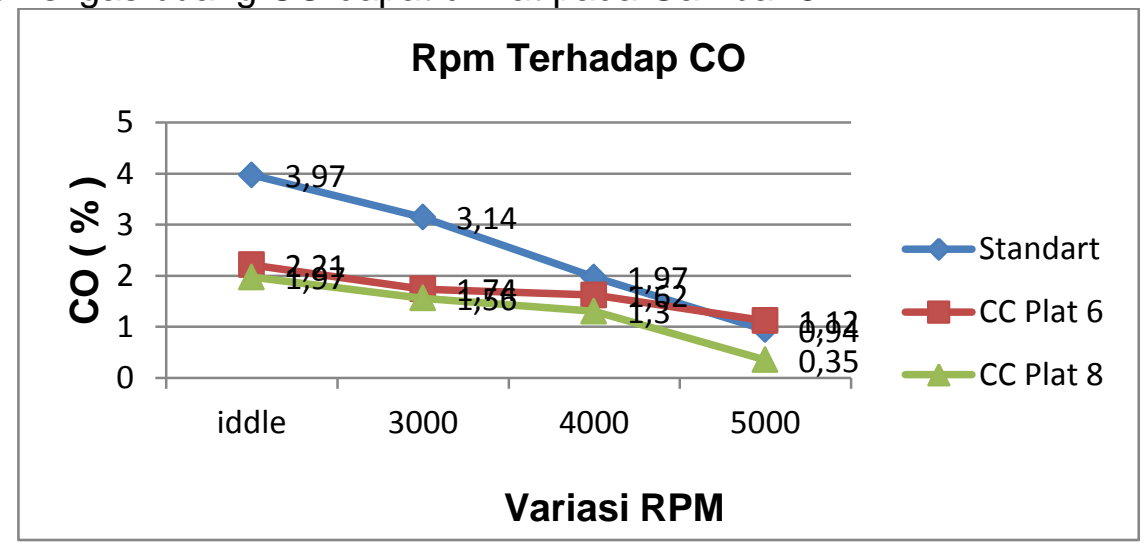

Gambar 8. Emisi Gas Buang CO 
Dari Gambar 8 dapat dilihat bahwa penggunaan Catalytic Converter dengan katalis kuningan ternyata mampu menaikkan konsentrasi emisi gas buang karbon dioksida (CO) secara signifikan dibandingkan dengan yang tidak menggunakan Catalytic Converter, motor yang digunakan untuk pengujian adalah shogun axelo 125 tahun 2010, Dengan penggunaan knalpot standar atau tanpa catalytic converter, dan menggunakan plat berbentuk 6 dan juga plat 8 dapat dilihat bahwa kandungan gas $\mathrm{CO}$ akan meningkat seiring dengan kenaikan RPM.

Pada Gambar 8 titik warna biru menunjukan konsentrasi emisi terhadap putaran mesin pada knalpot standar, titik warna merah menunjukan konsentrasi emisi terhadap putaran mesin pada knalpot catalytic converter berbentuk plat 6 , dan titik warna hijau menunjukan konsentrasi emisi terhadap putaran mesin pada knalpot catalytic coonverter berbentuk plat 8. Dapat diketahui bahwa semakin tinggi RPM maka hasil dari CO semakin menurun, hal ini disebabkan setiap perubahan RPM mengalami fluktuasi yang berbeda-beda, hal ini disebabkan karena jumlah bahan bakar yang masuk kedalam ruang bakar setiap perubahan RPM berbeda-beda. Disamping campuran bahan bakar yang masuk, juga dipengaruhi oleh kondisi kendaraan uji.

\section{Hasil Pengujian Catalytic Converter Terhadap Emisi Gas Buang HC dengan Variasi RPM}

Hasil emis gass buang HC dapat dilihat pada Gambar 9.

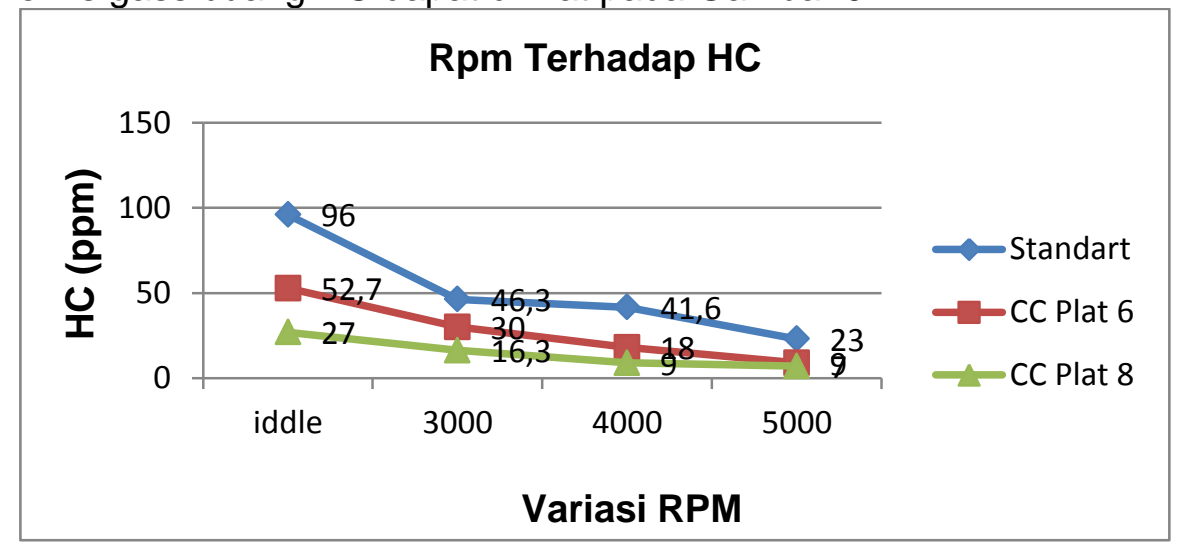

Gambar 9. Emisi Gas Buang HC

Dari Gambar 8 tersebut dapat dilihat bahwa penggunaan Catalytic Converter dengan katalis kuningan ternyata mampu menaikkan konsentrasi emisi gas buang karbon dioksida ( $\mathrm{HC})$ secara signifikan dibandingkan dengan yang tidak menggunakan Catalytic Converter, motor yang digunakan untuk pengujian adalah shogun axelo 125 tahun 2010, Dengan penggunaan knalpot standar atau tanpa catalytic converter, dan menggunakan plat berbentuk 6 dan juga plat 8 dapat dilihat bahwa kandungan gas $\mathrm{HC}$ akan meningkat seiring dengan kenaikan RPM.

Setiap kenaikan RPM mengalami penurunan nilai HC hal ini disebabkan oleh semakin tinggi RPM maka pencampuran antara udara dan bahan bakar semakin homogen yang menyebabkan pembakaran lebih sempurna sehingga nilai emisi HC semakin menurun disetiap RPM nya. 


\section{KESIMPULAN}

Dari penelitian yang telah dilakukan, dapat ditarik kesimpulan bahwa bentuk tanpa Catalytic Converter atau standar didapat kadar penurunan emisi $\mathrm{CO}_{2}$ maksimum sebesar 25,47 \%, kadar penurunan $\mathrm{CO}$ maksimum sebesar $76,32 \%$, kadar penurunan emisi $\mathrm{HC}$ maksimum sebesar $76,05 \%$. dengan variasi plat 8 (delapan) maka didapat kadar penurunan emisi $\mathrm{CO}_{2}$ maksimum sebesar $52,7 \%$, kadar penurunan emisi CO maksimum sebesar $82,23 \%$, dan kadar penurunan emisi HC maksimum sebesar $74,08 \%$. Bentuk catalytic converter dengan variasi plat 6 (enam) maka didapat kadar penurunan emisi $\mathrm{CO}_{2}$ maksimum sebesar 29,56\%, kadar penurunan emisi CO maksimum sebesar $49,32 \%$, dan kadar penurunan emisi HC maksimum sebesar $82,92 \%$.

\section{DAFTAR PUSTAKA}

Eka wahyudi amboro (2013). "Pengaruh penggunaan metallic catalytic converter berbahan kuningan dan aplikasi teknologi sass terhadap emisi sepeda motor honda new mega pro" journal universitas negeri surabaya. JTM. Volume 01 Nomor $02,102-109$.

Irawan, RM Bagus .(2009), Efektifitas pemasangan catalytic converter kuningan terhadap penurunan emisi gas carbon monoksida pada kendaraan motor bensin, http://jurnal.unimus.ac.id. UNIMUS.

Iskandar, Amin. (2010), "Pengaruh penggunaan kuningan sebagai katalis pada saluran buang yamaha jupiter z tahun 2004 terhadap konsentrasi gas HC" Fakultas Keguruan dan IImu Pendidikan. Universitas Sebelas Maret . Surakarta.

Dhimas Triadi Setyawan. (2015). "Perbandingan emisi gas buang antara motor bakar empat langkah berbahan bakar premium, pertalite dan elpiji" Fakultas Teknik . universitas jember . Jember.

Imam murdianto. (2016) "Perbedaan Performa (Daya, Torsi ,Konsumsi Bahan Bakar) Menggunakan Injector Standart dan Injector Racing dengan Bahan Bakar Pertamax dan Pertamax Plus pada Sepeda Motor v-xion" Tugas Akhir Teknik Mesin, UNNES, Semarang.

Mokhtar ali,Supriyanto Hery,Yulianto fajar. 2016. Catalytic converter jenis katalis kawat kuningan berbentuk sarang laba-laba untuk mengurangi emisi kendaraan bermotor, Malang. 